\title{
Vaccines and SARS-CoV-2 Variants-An Indian Perspective
}

\author{
Mohammad Arfat Ganiyani ${ }^{1,2}$, Manas Pustake ${ }^{1,2 *}$, \\ Isha Tambolkar ${ }^{3}$, Zaid Memon ${ }^{4}$ and Sunita Bhandari ${ }^{5}$ \\ ${ }^{1}$ Department of Microbiology, Grant Government Medical College and Sir JJ Group of \\ Hospitals, Mumbai, 400008, India \\ ${ }^{2}$ Dedicated Jumbo COVID Hospital, MMRDA Ground, Bandra Kurla Complex, \\ Bandra (E), Mumbai - 400 051, India \\ ${ }^{3}$ Department of Microbiology, BJ Government Medical College and Sassoon Hospital, \\ Pune, 411001, India \\ ${ }^{4}$ Department of Medical Virology, MGM Medical College, Navi Mumbai, 410 219, India \\ ${ }^{5}$ Department of Microbiology, S.M.B.T Institute of Medical Sciences and Research Center, \\ Dhamangaon, Nashik, India \\ *Corresponding author
}

Keywords

Virus, mutations,

vaccinations,

Coronavirus-2,

surveillance system

Article Info

Accepted:

14 April 2021

Available Online:

10 May 2021
SARS (Severe Acute Respiratory Syndrome) Coronavirus-2 (SARS-CoV-2) is a highly contagious virus that infects humans and several mammals, resulting in Coronavirus disease-19 (COVID-19). Every time the virus replicates, there is a chance that a mutation will occur, resulting in the development of a phylogenetically distinct strain. The emergence of several strains of this virus has resulted in a second wave of the epidemic and a tremendous amount of strain on the national surveillance and health systems. However, if we want to mount the most effective resistance against COVID-19, we must do so against variants as well, and for doing so, we must first consider the virus's evolutionary capacity. To foresee the variants that will emerge, it is important to understand how SARS-CoV-2 mutates and what limits its evolution. So far, the receptor-binding spike protein has been the focus, but the virus is a trailblazer, expressing 26 proteins that communicate with a broad variety of host factors, so the possibilities for evolution are numerous and uncertain. A triple mutant strain could be India's next challenge, and collecting as much information as possible about it is crucial to defeat it before it creates havoc. To bring an end to the COVID19 pandemic, widespread immunity to SARS-CoV-2 will be needed.

\section{Introduction}

Severe acute respiratory syndrome Coronavirus-2 (SARS-CoV-2) is a highly infectious virus that infects humans and various animals, resulting in coronavirus disease-19 (COVID-19), a respiratory distress syndrome that has triggered a worldwide 
pandemic and a severe health problem in the world's nations. Any time the virus reproduces, there is the possibility of a mutation resulting in the formation of a phylogenetically different strain. The evolution of many variants of this virus has caused a second wave and an enormous amount of stress on the national surveillance system and health system. And, as we can now see all over the globe, some resulting mutations and the resulting variants continue to jeopardize the effectiveness of all clinical management and vaccinations. The SARSCoV-2 variants and their further phylogenic enhancement will play a role in living with COVID-19. We, as a country, will need a strong health structure and defined policies to combat this tragic situation.

\section{Mechanism of mutation}

Despite Coronaviruses having the ability to proofread and draw out mismatched nucleotides throughout genome duplication and transcription, they are prone to mutation. As we know, the majority of the anti-viral drugs are nucleoside and nucleotide analogs. It has been a stumbling block to the production of anti-corona viral drugs (1). And, it showed around the world, the resulting variations risk lowering vaccine effectiveness.

A recent study to determine whether four different types of antibodies to the spike antigen, which individually and in combination neutralize SARS-CoV-2, are developing resistance showed that antibodies to spike mutants that have appeared in the human community are still successful.

However, after in vitro passing in the availability of individual antibodies, new spike mutants emerged quickly, resulting in insufficient neutralization (2); from this experiment, it is certain that new mutants will resist being neutralized by current antibodies.

\section{Strains of SARS-CoV-2}

Strains of concern of the novel coronavirus identified so far:

In December 2020, a strain named B.1.1.7 was discovered for the first time in the United Kingdom.

B.1.351 was discovered in December 2020 in South Africa.

P.1, first reported in Japan from a tourist from brazil in January 2021.

B.1.617- A research detected an emerging SARS-CoV-2 variant through viral entire sequencing of 2,172 nasal samples collected from 44 counties in California, a Western US state. In vivo, the mutant is $20 \%$ more communicable and has a 2-fold rise in shedding, it also showed that antibody had reduced efficiency in neutralizing this variant (3).

This predominant strain in California has a mutation (labeled L452R) that is also present in B.1.617 (double mutant) of India (4).

India's next challenge may be a triple mutant virus, and collecting as much information as possible about it is crucial in order to contain it before it creates havoc. A triple mutant is a variant made up of three different strains that have fused to form a single one. Two of these triple-mutant varieties were discovered in samples from Maharashtra, Delhi, West Bengal, and Chhattisgarh. Experts expressed concern and called for faster gene sequencing to fully comprehend the mutant (5).

\section{Antibody and neutralization}

Once an infection occurs, it takes several days to weeks for an active immune response to occur. As the infection subsides, plasma 
neutralization function began to decline several weeks after. The neutralizing action is needed for convalescent plasma transfer to be effective in infected patients. The convalescent plasma should be collected rapidly following the donor's recovery from active infection (6). Another mechanism is attributable to nanoparticles present on SARSCoV-2. Nanoparticles evoke neutralizing antibodies to variousthe variants due to their long persistence in lymph nodes and germinal centers. This nanoparticle had 6-fold greater retention, 4-fold greater appearance on follicular dendritic cell dendrites, and 5times increased germinal core reactions in lymph nodes than the soluble spike antibody against this nanoparticle gave a robust immune response in that experiment without any variation among different variants (7). For instance, a study conducted by Jassica Plantae et al., reported Hamsters contaminated with SARS-CoV-2 displaying spike(D614G orG614) had elevated infectious titers in nasal and the tracheal samples, though not in the lungs, corroborating clinical evidence the mutation boosts viral loads in COVID-19 patients' upper respiratory tracts and could improve transmission. Sera from hamsters infected with D614 virus mutant had somewhat higher neutralization titers against G614 virus mutant than against D614 strain, implying that the mutation is unlikely to reduce vaccines' capacity to defend against COVID-19 in clinical trials, and that therapeutic antibody should be checked against the circulating G614 virus.(8) Moreover, in vitro studies demonstrated decreased neutralization activity against the B.1.1.7 variant relative to a non-B.1.1.7 variant. However, the vaccine demonstrated effectiveness against the SARS-CoV-2 B.1.1.7 variant.(9)In the COVID-19 response, the Lancet COVID-19 Commission calls for measures like all areas with a high rate of new COVID-19 incidents, including the United States and the European Union (EU), should step up attempts to decrease population spread even while administering COVID-19 vaccines quickly (10).

\section{Vaccine}

Although many vaccines are developed to date for this disease, their efficacy is still a question. While the currently commercialized mRNA-1273 (moderna) vaccine appears successful, many questions remain about the vaccine's long-term effectiveness against emerging SARS-CoV-2 variants (11).

According to an ICMR report, Bharat Biotech's COVAXIN is successful against multiple SARS-CoV-2 variants, and neutralizes the double mutant of Covid-19 (12).

\section{Evidence of Reinfection}

SARS-CoV-2 501Y.V2 (B.1.351), a new lineage of the coronavirus responsible for COVID-19, incorporates several mutations in the spike protein's two immunodominant domains. We demonstrate here that this lineage is fully immune to three types of clinically important monoclonal antibodies. Additionally, 501Y.V2 evades neutralizing antibodies in COVID-19 convalescent plasma in a significant or full manner.

These findings emphasized the possibility of reinfection of antigenically distinguished variants, and could portend a decline in the effectiveness of currently available spikebased vaccines (13). A research was performed to determine if early COVID-19 convalescent patients' neutralizing antibody responses are successful against the two SARS-CoV-2 mutants B.1.1.7 and B.1.351. it demonstrated that B.1.351 mutation is significantly less susceptible to early pandemic plasma antibodies from previously infected CoVID patients (14). 
In conclusion, to put an end to the COVID-19 pandemic, pervasive immunity to SARS-CoV2 would be needed.

To predict the variants that will arise, it is critical to understand how SARS-CoV-2 mutates and what restricts its evolution. The receptor-binding spike protein has been the target so far, but the virus is sophisticated, encoding 26 proteins that interact with a wide range of host factors, so the opportunities for evolution are numerous and unpredictable. However, if we are to mount the strongest resistance against COVID-19, we must do so against mutants, and do so, we must understand the virus's evolutionary potential (15).

In the COVID-19 response, the Lancet COVID-19 Commission calls for measures like all areas with a high rate of new COVID19 incidents, including the United States and the European Union (EU), should step up attempts to decrease population spread even while administering COVID-19 vaccines quickly.

Mutation hotspots located near catalytic site of viral polymerase may challenge therapeutic effect remdesivir this indicate the need for genomic surveillance of such spots and use of this knowledge in diagnostic and therapeutic challenges (CLDC, KAT, and PMB 2021)

\section{References}

1. Robson F, Khan K S, Le T K, Paris C, Demirbag S, Barfuss $\mathrm{P}$, et al., Coronavirus RNA Proofreading: Molecular Basis and Therapeutic Targeting. Vol. 79, Molecular Cell. Cell Press; 2020. p. 710-27.

2. Baum A, Fulton B O, Wloga E, Copin R, Pascal K E, Russo V, et al., Antibody cocktail to SARS-CoV-2 spike protein prevents rapid mutational escape seen with individual antibodies. Science (80-). 2020 Aug;369(6506):1014-8.

3. Deng X, Garcia-Knight M A, Khalid M M, Servellita V, Wang C, Morris M K, et al., Transmission, infectivity, and neutralization of a spike L452R SARSCoV-2 variant. Cell. 2021 Apr;0(0).

4. "Double Mutant" Variant In India Shouldn't Really Be Called That, Scientists Say: Goats and Soda : NPR.

5. Triple Mutant Appearing in Indias Virus Variant, What it Means.

6. Beaudoin-Bussières G, Laumaea A, Anand S P, Prévost J, Gasser R, Goyette $\mathrm{G}$, et al., Decline of humoral responses against sars-cov-2 spike in convalescent individuals. MBio. 2020 Sep;11(5):1-7.

7. Zhang Y-N, Paynter J, Fourfouris T, Sou C, Ngo T, He L, et al., Mechanism of a COVID-19 nanoparticle vaccine candidate that elicits a broadly neutralizing antibody response to SARSCoV-2 variants. bioRxiv Prepr Serv Biol. 2021 Mar;

8. Plante J A, Liu Y, Liu J, Xia H, Johnson B A, Lokugamage $\mathrm{KG}$, et al., Spike mutation D614G alters SARS-CoV-2 fitness. Nature. 2021 Apr;592(7852):11621.

9. Emary K R W, Golubchik T, Aley P K, Ariani C V., Angus B, Bibi S, et al., Efficacy of ChAdOx1 nCoV-19 (AZD1222) vaccine against SARS-CoV-2 variant of concern 202012/01 (B.1.1.7): an exploratory analysis of a randomised controlled trial. Lancet. 2021 Apr;397(10282):1351-62.

10. Sachs J D, Abdool Karim S, Aknin L, Allen J, Brosbøl K, Cuevas Barron G, et al., Priorities for the COVID-19 pandemic at the start of 2021: statement of the Lancet COVID-19 Commission. Vol. 397, The Lancet. Elsevier B.V.; 2021. p. 947-50.

11. Noor R. Developmental Status of the Potential Vaccines for the Mitigation of 
the COVID-19 Pandemic and a Focus on the Effectiveness of the Pfizer-BioNTech and Moderna mRNA Vaccines. Curr Clin Microbiol Reports. 2021 Mar;

12. COVAXIN Neutralises Multiple Covid19 Variants Including Double Mutant Strain, Says ICMR Study.

13. Wibmer C K, Ayres F, Hermanus T, Madzivhandila $\mathrm{M}$, Kgagudi $\mathrm{P}$, Oosthuysen B, et al., SARS-CoV-2 501Y.V2 escapes neutralization by South African COVID-19 donor plasma.
bioRxiv Prepr Serv Biol. 2021 Jan;

14. Vidal S J, Collier A-RY, Yu J, McMahan $\mathrm{K}$, Tostanoski L H, Ventura J D, et al., Correlates of Neutralization Against SARS-CoV-2 Variants of Concern by Early Pandemic Sera. J Virol. 2021 Apr;

15. Luo R, Delaunay-Moisan A, Timmis K, Danchin A. SARS-CoV-2 biology and variants: anticipation of viral evolution and what needs to be done. Environ Microbiol. 2021;

\section{How to cite this article:}

Mohammad Arfat Ganiyani, Manas Pustake, Isha Tambolkar, Zaid Memon and Sunita Bhandari. 2021. Vaccines and SARS-CoV-2 Variants-An Indian Perspective. Int.J.Curr.Microbiol.App.Sci. 10(05): 502-506. doi: https://doi.org/10.20546/ijcmas.2021.1005.057 